\title{
Perceptions of diabetes obtained through drawing in childhood and adolescence
}

This article was published in the following Dove Press journal:

Patient Preference and Adherence

19 June 2013

Number of times this article has been viewed

Pilar Isla Pera'

María Palacin Lois ${ }^{2}$

Carmen López Matheu'

María Honrubia Pérez'

Ana María Gómez

Rodriguez ${ }^{3}$

Eulalia Armengol Camps ${ }^{4}$

Carmen Sanchez Villalba ${ }^{5}$

Roser Insa Soria ${ }^{6}$

Assumpta Rigol Cuadra'

Diana Marre ${ }^{7}$

'Nursing School, University of Barcelona, Barcelona, Spain; ${ }^{2}$ Facultad

Psicologia, University of Barcelona,

Barcelona, Spain; ${ }^{3}$ Endocrinology

Unit, Hospital Sant Joan de Deu,

Barcelona, Spain; ${ }^{4}$ Endocrinology

Unit, Hospital Vall d'Hebrón,

Barcelona, Spain; ${ }^{5}$ Sanatorium Hospital

Foundation The Holy Spirit, Santa

Coloma de Gramenet, Catalonia,

Spain; ${ }^{6}$ Endocrinology Unit, Hospital

Universitari de Bellvitge, Barcelona,

Spain; ${ }^{7}$ Antropologia Social y Cultural,

Universitat Autònoma de Barcelona,

Barcelona, Spain
Correspondence: Pilar Isla Pera

Nursing School, Campus Universitario

Ciencias de la Salut, University of

Barcelona, Feixa Llarga s/n L'Hospitalet

de Llobregat 08907, Barcelona, Spain

Tel +3493402 424l

Email pisla@ub.edu
Objective: To examine whether drawing is useful in the detection of problems of psychosocial adaptation in children and adolescents with type 1 diabetes (T1D) and in improving communication with health professionals.

Methods: We performed an exploratory descriptive study in 199 children and adolescents with T1D aged 4-13 years. The participants were asked to render a drawing on a suggested topic. The variables analyzed were related to the drawing and to clinical and sociodemographic data.

Results: Most participants showed evidence of having a well-balanced personality, but there were also signs of affective or psychosocial difficulties.

Conclusion: Drawing is a useful technique by which to identify children's and adolescents' feelings and possible problems in adapting to T1D, as well as to gain information directly from the children themselves. Future studies should delimit the possibilities of this technique in clinical practice in greater detail.

Keywords: type 1 diabetes mellitus, childhood and adolescence, drawing, psychosocial factors

\section{Introduction}

An estimated 480,000 children and adolescents aged less than 15 years have type 1 diabetes (T1D), ${ }^{1}$ of which 29,000 live in Spain. ${ }^{2}$ Children and adolescents with T1D have to tolerate insulin therapy, blood glucose measurement, dietary control, medical visits, and the threat of acute or chronic complications. Young people are able to perceive the emotional effects of their disease on their families and may feel as though they are different from their peers at school or in their social environment. All of these factors make them vulnerable and may lead to alterations in their psychological and social development, hampering their progressive involvement in self-care. ${ }^{3,4}$ Numerous studies have identified mental health disturbances in children and adolescents with T1D and their families and have shown the importance of effective communication with the health team to improve the effectiveness of health care programs, therapeutic education (TE), and the quality of life of young diabetic patients and their families. ${ }^{5-10}$

Drawing has been used in pedagogy to analyze the development of the education process ${ }^{11}$ and to evaluate health education programs. ${ }^{12}$ This technique has also been used to study the characteristics of personality development ${ }^{13,14}$ and, in the last few years, has been increasingly employed to study the effects of particular experiences. ${ }^{15-23}$ Drawing is more reliable than verbal communication in persons with limited verbal capacity, introspective ability, or maturity, but who are nevertheless able to symbolize their experiences..$^{24}$ Unwanted feelings, those for which a child has no words or that are 
too emotionally charged to be thought about clearly, may be better expressed through drawing than through words. ${ }^{24}$ This technique allows young people to express their perceptions and opinions freely, unbiased by questions prompted by the researcher's own interest. ${ }^{25}$ It is accepted that the figure drawn represents the experience of the child and his or her needs and preferences. ${ }^{13}$ Drawings are a "window" to a young person's thoughts and feelings, because they provide an image of their particular world. ${ }^{15,16}$ This technique is both economical and easily performed, since it requires few resources and children generally enjoy the activity. ${ }^{16}$

Since the 1980s, research into the possible value of drawings as a tool by which to evaluate emotional difficulties has grown. Although authors disagree on various issues, there is general agreement that some characteristics of drawings reflect certain emotional features or problems in children. ${ }^{16,26-32}$ Drawing is also useful in encouraging communication between the child and the health team when relationships are strained by stress and the strong feelings provoked by diagnosis or treatment. ${ }^{16,21}$ Stressed children tend to show more emotional indicators in their drawings than their non-stressed peers. ${ }^{33}$ Very few analyses have been carried out in children with T1D; some of these form parts of studies of nonspecific chronic diseases. ${ }^{34,35}$ There are, however, other possible sources of information on young people's experiences of diabetes. For example, a webpage on childhood diabetes may include a section where children exchange their drawings, songs, or poems about their experiences of the disease ${ }^{36}$ some art therapy activities have been initiated; and distinct pharmaceutical companies have sponsored drawing competitions for children with diabetes mellitus. The results of these initiatives, however, have not been analyzed.

The general aim of this study was to examine whether drawing is useful in detecting problems of psychosocial adaptation in children and adolescents with T1D. Secondary objectives were to determine the clinical and sociodemographic profiles of children and adolescents with $\mathrm{T} 1 \mathrm{D}$ and to determine whether there is a relationship between their drawings and their clinical and sociodemographic variables.

\section{Methods}

We performed an observational, cross-sectional, exploratory study. The setting consisted of three hospitals within the publicly funded health service of Catalonia, Spain, situated in Barcelona and with specialized units for the care of diabetic children. Participants were children and adolescents aged between 4 and 13 years with a diagnosis of T1D. The inclusion criteria consisted of a diagnosis of T1D 6 months previously or more; the absence of any other chronic diseases, cognitive deficit or physical disability; and adequate language skills (the ability to speak Spanish or Catalan). Exclusion criteria consisted of attendance at the unit for an acute complication of T1D; living in a children's home or boarding school; and refusal to participate. The 4 year age range was chosen because the child's cognitive stage was a factor when drawings were interpreted by age. In general, children under 4 years old produce drawings without clearly defined images or ideas and tend to draw imaginative-figurative elements. After that age, children tend to produce images from the real world or taken from fiction. ${ }^{15}$

During 2009, children who attended the participating units and who met the inclusion criteria were recruited. To facilitate trust, the person asking the child to produce the drawing was a nurse, who suggested the theme of "diabetes and me." All participating centers offered the same material: an A4 sheet of white drawing paper, pencils, ballpoint pens, felt-tip pens, and colored crayons of various sizes. The children made the drawing in the room of therapeutic education unit, before medical consultation and they were given 30 minutes to complete the drawing. In psychology, the most commonly used drawing techniques for the researchers are free drawing, drawing a human figure, the family, selfportraits, a tree, or a suggested topic. The latter was chosen because this technique identifies how concepts of objects and situations are formed in the child's consciousness, and the importance they have in their repertoire affective. ${ }^{17,37,38}$ Furthermore, a specific topic allows comparisons to be made among participants sharing a common problem.

After 30 minutes, the children were asked to talk about their drawings, and their explanations were transcribed literally. Other variables were also gathered: age at diagnosis of T1D; current age; sex; disease duration; acute complications in the last year; number of hypoglycemic episodes per week; chronic complications; last $\mathrm{HbA}_{1 \mathrm{c}}$ value; attendance at camps for diabetic children; participation in educational activities organized by patient associations or health centers; number of siblings and the birth order of the participating child; and family history of T1D. To evaluate the degree of metabolic control, acceptable values by age were established, following the protocol of the participating hospitals. Acceptable values were defined as $\mathrm{HbA}_{1 \mathrm{c}}<8.5 \mathrm{mg} / \%$ in $4-6$ year-olds; $<8 \mathrm{mg} / \%$ in 7-12 year olds; and $<7.5 \mathrm{mg} / \%$ in 13 -year-olds.

To analyze the drawings, the variables selected as being the most representative were color, stroke, size, 
and symmetry. Color is a symbolic element of communication: red is associated with vitality, courage, passion and negatively - with aggression, if the drawing depicts conflict; pink is associated with sensitivity, affect, and a preference for an ideal world; green is associated with tranquility, hope, and sensitivity; blue suggests balance and introspection; orange indicates sociability; yellow communicates curiosity and joy; violet or purple is associated with sadness; gray with insecurity; brown with stability; and black with fear, anxiety, and distress, or - positively - with self-confidence, if this quality is consonant with the theme of the drawing. Drawings with multiple colors indicate joy, curiosity, and motivation, while those with few colors denote lack of interest and motivation. Fearful children do not usually color in their drawings. ${ }^{39-42}$

Size provides information on self-esteem. Small drawings can be interpreted as indicating a feeling of inferiority, while large drawings are associated with extraversion and, if they exceed the dimension of the paper, with aggression. ${ }^{39-42}$

Stroke is related to the drawer's energy. Weak strokes show signs of inhibition and repression, medium strokes show greater emotional control, and strong strokes indicate assertiveness and aggression, if marked. ${ }^{41}$

A lack of symmetry is related to insecurity. ${ }^{41,42}$ Children usually draw themselves in the center of the sheet, indicating that they perceive themselves at the center of their world, and place the symbolic representations related to their egos in the surrounding area. A drawing covering the whole sheet indicates that the child is extraverted, dynamic, and participative, while a drawing occupying only a small part of the sheet suggests a child who is shy, inhibited, or withdrawn.

All of the abovementioned factors were used to guide the graphic analysis of the drawings. In addition, to increase the validity of the study, drawings were classified by their overall impression in relation to their content and structure (joy, sadness, worry, confusion, and self-care); a joint variable for negative emotional indicators (asymmetry, smallness, weak or shaky strokes, and absence of color or only one or two colored strokes) was designed, which grouped drawings into those with no negative emotional indicators, and those with one, two, or three or more of these indicators. Finally, the drawings were grouped into categories according to their theme. The research team used team consensus for the classification of the drawings.

The statistical analysis was carried out with the SPSS statistical package (v 18.0; IBM Corporation, Armonk, NY, USA). A descriptive analysis was performed of the clinical, sociodemographic, and drawing-related variables. Measures of central tendency and dispersion were calculated in quantitative variables and frequencies and percentages in qualitative variables. The corresponding 95\% confidence intervals were calculated. For the bivariate analysis, the $\chi^{2}$ test, Fisher's exact test, Student's $t$-test, analysis of variance (ANOVA), or the Mann-Whitney U-test were used, depending on the type of variable. Lastly, a multivariate analysis was performed through simple linear regression. A $P$-value equal to or less than 0.05 was considered statistically significant.

\section{Ethical aspects}

We explained the activity to be carried out and the aims of the project in detail before requesting the young person's voluntary collaboration. Informed consent was obtained from the parents and approval was granted by the ethics committees of the participating hospitals.

\section{Results}

A total of 199 children and adolescents were included in this study, equivalent to $25 \%$ of children with T1D in this age group who received public health care treatment in Barcelona, Spain. All the children were autochthonous and lived in Catalonia. Sociodemographic and clinical data are shown in Table 1. None of the patients had chronic complications. A total of $1.5 \%$ had experienced one episode of diabetic ketoacidosis and $14.6 \%$ had experienced between one and five episodes of diabetic ketoacidosis in the previous year. No significant differences were found by sex, age at disease onset, or current age.

$\mathrm{HbA}_{1 \mathrm{c}}$ values were above recommended levels in $61 \%$. Those with the highest percentage of altered $\mathrm{HbA}_{1 \mathrm{c}}$ levels were teenagers $(P=0.001)$ and children with a family history of diabetes mellitus $(P=0.02)$. On adjusting $\mathrm{HbA}_{1 \mathrm{c}}$ by current age, age at onset of T1D, number of hypoglycemic episodes, and T1D duration in months, significant differences were found by current age $(P=0.019)$, age at diabetes onset $(P=0.002)$, and the number of weekly hypoglycemic episodes $(P=0.05)$

A total of $15.6 \%$ of the participants had no brothers or sisters, while $41.7 \%$ had one sibling, and $34.2 \%$ had two. The remaining participants had between three and eight siblings. Among those with siblings, $40.7 \%$ were the eldest child in the family. Almost a quarter $(22.5 \%)$ had attended a diabetes camp and a further $22.5 \%$ had participated in educational activities organized by associations for diabetic patients. Significant differences were found by age and sex in attendance at camps $(P=0.03)$ and patient associations 


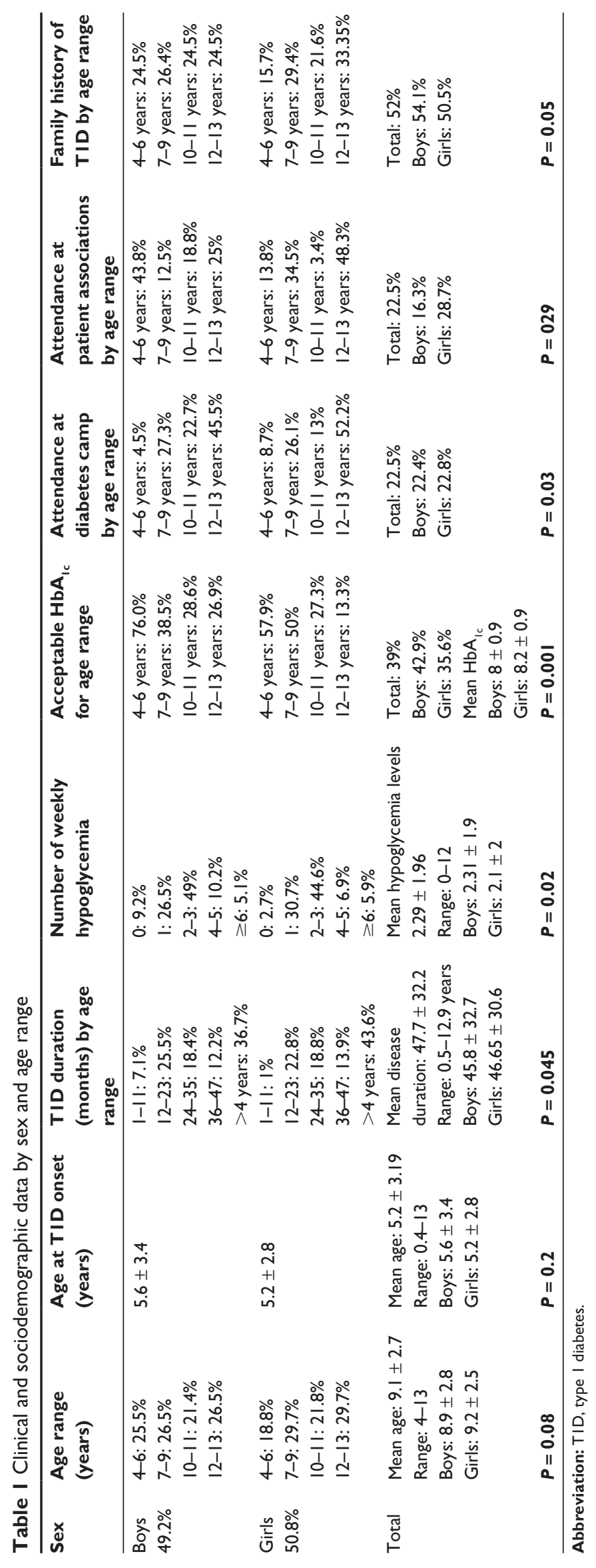


$(P=0.29)$. Slightly more than one-fifth $(22.1 \%)$ had attended structured TE courses in the hospital, and the remainder had received individualized TE from a nurse and pediatric endocrinologist. Just over half $(52.8 \%)$ of the participants had a family history of diabetes. In most cases, the affected family members were the grandparents $(59.6 \%)$ followed by the father or the mother (10.5\%), siblings (3.8\%), and other relatives $(26.1 \%)$. Ninety percent were receiving intensified insulin therapy and $10 \%$ were receiving continuous subcutaneous insulin infusion (CSII).

Two-thirds of the participants (69.6\%), included themselves in the drawing, the theme of which was "diabetes and me." Of these, $22.4 \%$ drew, together with the figure representing themselves, elements related to insulin; $16.3 \%$ depicted elements related to glycemic measurement; $8.1 \%$ included friends; $6.8 \%$ depicted foods they should and should not eat; $5.4 \%$ included at least one family member; $4.7 \%$ drew themselves as experiencing a hypoglycemic episode; $3.2 \%$ depicted themselves without alluding to the disease or its treatment; and $2.7 \%$ depicted diabetes in the form of a female figure, an animal, a ghost, the devil, a large insect, or a monster.

One third of the children (31.1\%) did not include themselves in the drawing. Of these, $7 \%$ drew insulin delivery devices and/or blood glucose monitors; $3.5 \%$ drew various parts of the body (pancreas, hands or fingers); $3.5 \%$ used metaphorical drawings (for example, a house with the door closed in which insulin can not enter) to describe their experience of the disease; $2.5 \%$ drew fantasy elements with no apparent relationship with themselves or with their disease (outer space, UFOs or animals); $2.2 \%$ drew sweets; $8.2 \%$ drew health professionals, hospitals, diabetic camps or their home; $4.2 \%$ drew other children with diabetes in their drawings, except one child (who drew a diabetic adult).

Overall, $50.8 \%$ rendered a colored drawing; $22.6 \%$ used two colors; $20.6 \%$ colored at least one stroke with one color; and $6 \%$ used only black. Nearly half $(47.7 \%)$ used medium strokes, $26.1 \%$ heavy strokes, $20.2 \%$ light strokes, and $6 \%$ shaky strokes. Lack of symmetry was found in $67.8 \%$ of the pictures. Size was classed as medium in $59.3 \%$ of the drawings, large in $21.6 \%$, and small in $17.6 \%$, and both large and small figures or objects were present in $1.5 \%$ of the drawings.

In terms of general impressions given by the drawings, $36.7 \%$ contained elements showing the importance of self-care (insulin administration, exercise, healthy diet, and glycemic control); $21.1 \%$ contained verbal or figurative expressions of sadness (crying, anger); 17.6\% showed worry (with oral expressions. eg "I have to improve," "I worry about so many hypoglycemia", having to control diet); $15.1 \%$ depicted joy (smiling faces or expressions suggesting "I'm OK" or "I'm happy"); and 9.5\% of the pictures were abstract or fantasy drawings.

There were no negative emotional indicators in $20.6 \%$ of the drawings; one negative indicator in $40.2 \%$; two negative indicators in $31.2 \%$; and three or more negative emotional indicators in $8 \%$. The drawings were grouped in the following thematic categories: suffering (47.7\%) (Figure 1); resilience (36.2\%) (Figure 2); confusion (8\%) (Figure 3); stigma (5\%) (Figure 4); and turmoil (3\%) (Figure 5). The term "illness," used in its anthropological sense, refers to the subjective experience of living with the disease and to the patient's perceptions of the disease. ${ }^{43}$

The characteristics of the drawings by age and sex are shown in Table 2. Significant differences were found in color $(P=0.032)$, stroke $(P=0.017)$, size $(P=0.01)$, symmetry $(P=0.01)$, the number of negative emotional indicators ( $P=0.009)$, and themes $(P=0.036)$; a nearly statistically significant difference was found for general impression given by the drawing $(P=0.06)$. Age range was associated with symmetry $(P=0.001)$ and with the number of negative emotional indicators $(P=0.045)$. The age range most frequently producing drawings with three or more negative emotional indicators was children aged $10-12$ years. Older children more frequently depicted stigma and resilience, but this finding was not statistically significant.

Participants experiencing between zero and one weekly hypoglycemic episodes produced more colored drawings than those with more hypoglycemic episodes $(P=0.03)$. $\mathrm{HbA}_{1 \mathrm{c}}$ was directly related to symmetry $(P=0.001)$ and to the number of negative emotional indicators $(P=0.005)$. No significant differences were found by family history of diabetes, attendance at diabetes camps or patient associations,

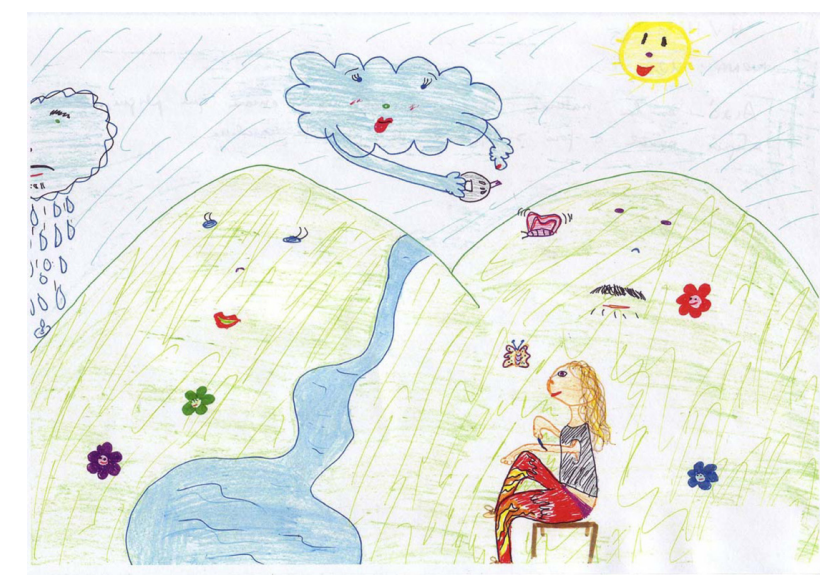

Figure I "I'm stabbing myself insulin and even rain, is cloud or make one, I must possess the insulin." Girl, 10 years. 


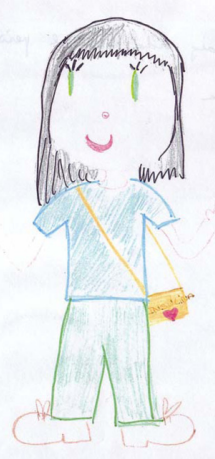

Figure 2 "I'm very happy. My life is normal but always carry the bag with insulin." Girl, 12 years.

or number of siblings; however, a significant difference was found by the birth order of children with T1D. Younger children with two or more older siblings expressed stronger feelings of stigma $(P=0.037)$ and sadness $(P=0.42)$ in their drawings.

\section{Discussion}

The descriptive analysis showed that disease onset occurred early in the participants of this study - at a mean age of 5.2 years. $\mathrm{HbA}_{1}$ values were above recommended levels in $61 \%$, indicating chronically inadequate glycemic control. Metabolic control was worst in adolescents. This finding agrees with reports in the literature and is caused both by difficulties in controlling blood glucose due to reduced insulin sensitivity in adolescence and by psychological factors at this age. ${ }^{6-8,44}$ Ten percent of participants had started treatment with CSII at the time of the study, and the remaining participants continued with intensified insulin therapy. Because of the low number

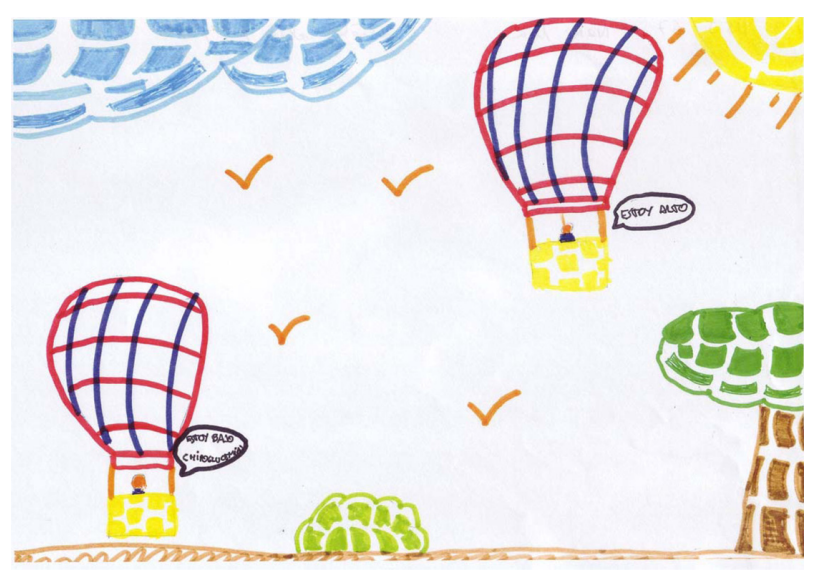

Figure 3 “Controls high and low. How hard!” Boy, II years.

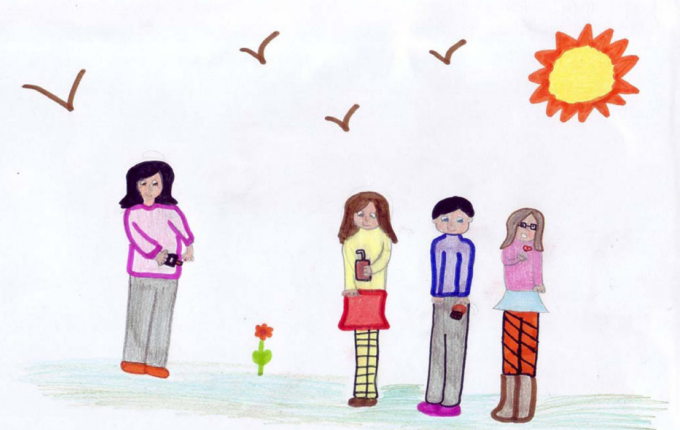

Figure 4 "The left is me l'm getting insulin. Those on the right are my friends who are taking chocolate and ice cream." Girl, II years.

of patients receiving CSII, intergroup differences could not be established.

We expected that children and families with a family history of diabetes would have greater knowledge of the disease and competence in self-care. Our results, however, show an inverse relationship between $\mathrm{HbA}_{1 \mathrm{c}}$ and a family history of the disease. Possible explanations are a reduced perception of risk as affected individuals become accustomed to the disease, leading to a relaxation of control, or higher levels of stress and anxiety interfering with self-care. It would be interesting to analyze this finding in future studies. Another surprising result was that $89.4 \%$ of the participants experienced at least one hypoglycemic episode per week and almost 50\% had between two and three hypoglycemic episodes weekly; these episodes were most frequent in participants with the best metabolic control. The aim of T1D treatment is to achieve adequate metabolic control to prevent or delay the development of chronic complications, reduce

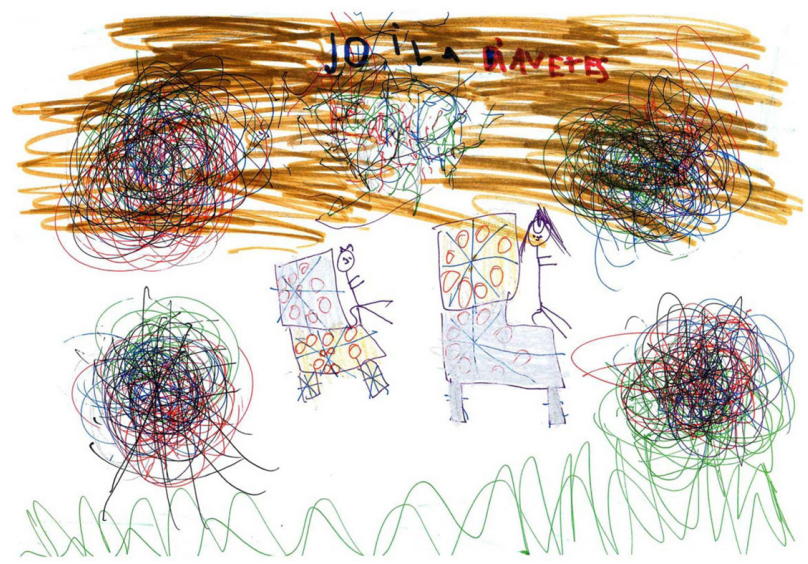

Figure 5 "Me and my mom at the site of diabetes." Boy, 7 years. 
Table 2 Characteristics of drawings by age and sex range

\begin{tabular}{|c|c|c|c|c|}
\hline Color & No color & $\begin{array}{l}\text { I or } 2 \text { colored } \\
\text { strokes }\end{array}$ & 2 colors & $>2$ colors \\
\hline \multirow[t]{4}{*}{ Boys } & $4-6$ years: $12 \%$ & $4-6$ years: $24 \%$ & $4-6$ years: $20 \%$ & $4-6$ years: $44 \%$ \\
\hline & 7-9 years: $3.8 \%$ & $7-9$ years: $19.2 \%$ & $7-9$ years: $19.2 \%$ & $7-9$ years: $57.7 \%$ \\
\hline & I0-II years: $9.5 \%$ & $10-1 \mid$ years: $23.8 \%$ & $10-1 \mid$ years: $23.8 \%$ & I0-II years: $42.9 \%$ \\
\hline & 12-13years: $15.4 \%$ & $12-13$ years: $26.9 \%$ & $12-13$ years: $30.8 \%$ & $12-13$ years: $26.9 \%$ \\
\hline \multirow[t]{4}{*}{ Girls } & 4-6 years: $5.3 \%$ & $4-6$ years: $21.1 \%$ & $4-6$ years: $21.1 \%$ & $4-6$ years: $52.6 \%$ \\
\hline & $7-9$ years: $0 \%$ & 7-9 years: $13.3 \%$ & $7-9$ years: $30 \%$ & $7-9$ years: $56.7 \%$ \\
\hline & I0-II years: $4.5 \%$ & $10-1 \mid$ years: $27.3 \%$ & $10-1 \mid$ years: $18.2 \%$ & $10-11$ years: $50 \%$ \\
\hline & $12-13$ years: $0 \%$ & $12-13$ years: $13.3 \%$ & $12-13$ years: $16.7 \%$ & $12-13$ years: $70 \%$ \\
\hline Stroke & Weak & Shaky & Medium & Strong \\
\hline \multirow[t]{4}{*}{ Boys } & $4-6$ years: $20 \%$ & $4-6$ years: $8 \%$ & $4-6$ years: $40 \%$ & $4-6$ years: $32 \%$ \\
\hline & $7-9$ years: $23.1 \%$ & $7-9$ years: $3.8 \%$ & $7-9$ years: $50 \%$ & $7-9$ years: $23.1 \%$ \\
\hline & 10-II years: $33.3 \%$ & I0-II years: $4.8 \%$ & $10-11$ years: $47.6 \%$ & I0-II years: $14.3 \%$ \\
\hline & $12-13$ years: $23.1 \%$ & $12-13$ years: $15.4 \%$ & $12-13$ years: $30.8 \%$ & $12-13$ years: $30.8 \%$ \\
\hline \multirow[t]{4}{*}{ Girls } & 4-6 years: $15.8 \%$ & $4-6$ years: $0 \%$ & $4-6$ years: $63.2 \%$ & $4-6$ years: $21.1 \%$ \\
\hline & $7-9$ years: $20 \%$ & $7-9$ years: $0 \%$ & $7-9$ years: $46.7 \%$ & $7-9$ years: $33.3 \%$ \\
\hline & I0-II years: $22.7 \%$ & I0-1I years: $0 \%$ & I0-II years: $50 \%$ & I0-II years: $27.3 \%$ \\
\hline & $12-13$ years: $20 \%$ & $12-13$ years: $0 \%$ & $12-13$ years: $56.7 \%$ & $12-13$ years: $23.3 \%$ \\
\hline Size & Large & Medium & Small & Varied \\
\hline \multirow[t]{4}{*}{ Boys } & $4-6$ years: $28 \%$ & $4-6$ years: $52 \%$ & $4-6$ years: $16 \%$ & 4-6 years: $4 \%$ \\
\hline & $7-9$ years: $26.9 \%$ & $7-9$ years: $61.5 \%$ & 7-9 years: $11.5 \%$ & 7-9 years: $0 \%$ \\
\hline & $10-11$ years: $14.3 \%$ & $10-11$ years: $61.9 \%$ & $10-11$ years: $23.8 \%$ & I0-II years: $0 \%$ \\
\hline & $12-13$ years: $34.6 \%$ & $12-13$ years: $38.5 \%$ & $12-13$ years: $23.1 \%$ & $12-13$ years: $3.8 \%$ \\
\hline \multirow[t]{4}{*}{ Girls } & $4-6$ years: $26.3 \%$ & $4-6$ years: $57.9 \%$ & $4-6$ years: $15.8 \%$ & $4-6$ years: $0 \%$ \\
\hline & $7-9$ years: $6.7 \%$ & $7-9$ years: $73.3 \%$ & $7-9$ years: $16.7 \%$ & 7-9 years: $3.3 \%$ \\
\hline & I0-II years: $4.5 \%$ & $10-11$ years: $63.6 \%$ & $10-1 \mid$ years: $31.8 \%$ & I0-II years: $0 \%$ \\
\hline & $12-13$ years: $3.3 \%$ & $12-13$ years: $63.3 \%$ & $12-13$ years: $33.3 \%$ & $12-13$ years: $0 \%$ \\
\hline Symmetry & Yes & No & & \\
\hline \multirow[t]{4}{*}{ Boys } & $4-6$ years: $0 \%$ & $4-6$ years: $100 \%$ & & \\
\hline & 7-9 years: II.5\% & $7-9$ years: $88.5 \%$ & & \\
\hline & I0-II years: $52.4 \%$ & $10-11$ years: $47.6 \%$ & & \\
\hline & $12-13$ years: $34.6 \%$ & $12-13$ years: $65.4 \%$ & & \\
\hline \multirow[t]{4}{*}{ Girls } & $4-6$ years: $10.5 \%$ & 4-6 years: $89.5 \%$ & & \\
\hline & $7-9$ years: $20 \%$ & $7-9$ years: $80 \%$ & & \\
\hline & I0-II years: $45.5 \%$ & $10-11$ years: $54.5 \%$ & & \\
\hline & $12-13$ years: $76.7 \%$ & $12-13$ years: $23.3 \%$ & & \\
\hline General impression & Self-care & Sadness & Worry & Joy \\
\hline \multirow[t]{4}{*}{ Boys } & $4-6$ years: $40 \%$ & $4-6$ years: $16 \%$ & $4-6$ years: $20 \%$ & $4-6$ years: $8 \%$ \\
\hline & $7-9$ years: $50 \%$ & $7-9$ years: $3.8 \%$ & $7-9$ years: $11.5 \%$ & 7-9 years: $15.4 \%$ \\
\hline & I0-II years: $28.6 \%$ & I0-II years: 33.3\% & $10-11$ years: $23.8 \%$ & I0-II years: $4.8 \%$ \\
\hline & $12-13$ years: $26.9 \%$ & $12-13$ years: $34.6 \%$ & $12-13$ years: $19.2 \%$ & $12-13$ years: $7.7 \%$ \\
\hline \multirow[t]{4}{*}{ Girls } & $4-6$ years: $42.1 \%$ & $4-6$ years: $21.1 \%$ & $4-6$ years: $5.3 \%$ & $4-6$ years: $26.3 \%$ \\
\hline & $7-9$ years: $40 \%$ & 7-9 years: $13.3 \%$ & $7-9$ years: $23.3 \%$ & $7-9$ years: $20 \%$ \\
\hline & I0-II years: $45.5 \%$ & $10-1 \mid$ years: $18.2 \%$ & I0-1I years: $13.6 \%$ & I0-1I years: $13.6 \%$ \\
\hline & $12-13$ years: $23.3 \%$ & $12-13$ years: $30 \%$ & $12-13$ years: $20 \%$ & $12-13$ years: $23.3 \%$ \\
\hline $\begin{array}{l}\text { Negative emotional } \\
\text { indicators }\end{array}$ & 0 & I & 2 & 3 or more \\
\hline \multirow[t]{4}{*}{ Boys } & $4-6$ years: $0 \%$ & $4-6$ years: $44 \%$ & $4-6$ years: $44 \%$ & $4-6$ years: $12 \%$ \\
\hline & $7-9$ years: $15.4 \%$ & $7-9$ years: $34.6 \%$ & $7-9$ years: $42.3 \%$ & $7-9$ years: $7.7 \%$ \\
\hline & I0-II years: $28.6 \%$ & $10-1 \mid$ years: $38.1 \%$ & 10-1I years: $19 \%$ & I0-II years: $14.3 \%$ \\
\hline & $12-13$ years: $11.5 \%$ & $12-13$ years: $34.6 \%$ & $12-13$ years: $38.5 \%$ & $12-13$ years: $15.4 \%$ \\
\hline \multirow[t]{4}{*}{ Girls } & $4-6$ years: $15.8 \%$ & $4-6$ years: $31.6 \%$ & $4-6$ years: $47.4 \%$ & $4-6$ years: $5.3 \%$ \\
\hline & $7-9$ years: $17.7 \%$ & $7-9$ years: $56.7 \%$ & $7-9$ years: $26.7 \%$ & $7-9$ years: $0 \%$ \\
\hline & I0-II years: $22.7 \%$ & I0-II years: $45.5 \%$ & $10-1 \mid$ years: $22.7 \%$ & I0-1I years: $9.1 \%$ \\
\hline & $12-13$ years: $50 \%$ & $12-13$ years: $33.3 \%$ & $12-13$ years: $13.3 \%$ & $12-13$ years: $3.3 \%$ \\
\hline
\end{tabular}

(Continued) 
Table 2 (Continued)

\begin{tabular}{|c|c|c|c|c|c|}
\hline Themes & IIIness & Resilience & Confusion & Stigma & Turmoil \\
\hline \multirow[t]{4}{*}{ Boys } & $4-6$ years: $60 \%$ & $4-6$ years: $20 \%$ & 4-6 years: $16 \%$ & 4-6 years: $4 \%$ & 4-6 years: $0 \%$ \\
\hline & $7-9$ years: $42.3 \%$ & $7-9$ years: $34.6 \%$ & 7-9 years: II.5\% & $7-9$ years: $0 \%$ & 7-9 years: II.5\% \\
\hline & I0-II years: $52.4 \%$ & I0-II years: $28.6 \%$ & I0-II years: $14.3 \%$ & I0-II years: $4.8 \%$ & I0-II years: 0\% \\
\hline & $12-13$ years: $61.5 \%$ & $12-13$ years: $26.9 \%$ & $12-13$ years: $3.8 \%$ & $12-13$ years: $3.8 \%$ & $12-13$ years: $3.8 \%$ \\
\hline \multirow[t]{4}{*}{ Girls } & 4-6 years: $47.4 \%$ & 4-6 years: $42.1 \%$ & 4-6 years: $5.3 \%$ & 4-6 years: $0 \%$ & $4-6$ years: $5.3 \%$ \\
\hline & $7-9$ years: $46.7 \%$ & $7-9$ years: $46.7 \%$ & $7-9$ years: $3.3 \%$ & $7-9$ years: $3.3 \%$ & $7-9$ years: $0 \%$ \\
\hline & I0-II years: $45.5 \%$ & I0-II years: $36.4 \%$ & I0-II years: $9.1 \%$ & I0-II years: $4.5 \%$ & I0-II years: $4.5 \%$ \\
\hline & $12-13$ years: $30 \%$ & $12-13$ years: $50 \%$ & $12-13$ years: $3.3 \%$ & $12-13$ years: $16.7 \%$ & $12-13$ years: $0 \%$ \\
\hline
\end{tabular}

acute complications - especially hypoglycemic episodes, and achieve good quality of life; however, achieving these goals with conventional treatment is hampered by children's and adolescents' physiological, psychological, social, and emotional characteristics. ${ }^{44}$ Importantly, however, children and adolescents are also at risk of developing complications. Twelve years after diagnosis, more than 50\% develop complications or comorbidities. ${ }^{44}$ At all ages, mortality is higher in children with T1D than in their disease-free peers and is generally due to acute complications. ${ }^{45,46}$

A notable finding was the low attendance at diabetic camps, given that the aim of these is to provide young people with knowledge about their disease, skills for its management, and opportunities to share experiences with their diabetic peers, as well as to improve their TE, autonomy, and quality of life. This finding can be explained in children aged 4-6, since attendance at camps starts at the age of 6 years; even so, less than $50 \%$ of $10-13$ year olds had attended at least once.

Analysis of the drawings and their explanations indicated that most participants had well-balanced personalities with appropriate-for-age objectivity, extraversion, maturity, energy, self-control, sensitivity, originality, and empathy. Some data, nevertheless, could indicate affective or psychosocial difficulties. One-quarter (26.4\%) did not include themselves in their drawings, even though the theme of the activity was "diabetes and me," possibly indicating failure to accept the disease. Irrespective of whether participants included themselves in their drawings or not, the most commonly included elements were insulin injections, glycemic monitoring, and diet, indicating that treatment and metabolic control were the most important aspects of the disease to the participants, sometimes positively - to control the disease and sometimes negatively, in the form of worry and rejection of the disease. Importantly, the disproportionately large size of needles and blood drops in many of these drawings indicate the huge impact of these techniques in the participants' lives.
Some participants personified diabetes as an inseparable friend, a devil that held them prisoner, a devouring elephant, an enormous insect, a ghost that, if touched, triggered the disease, or as a threatening, hostile environment. Symbolic images, such as bothersome elements (eg black tunnels, dark houses, storms etc), or aggressive or legendary animals symbolizing the "harmer" are frequent in the drawings of cancer patients. ${ }^{47}$

$\mathrm{HbA}_{1 \mathrm{c}}$ levels were higher in girls than in boys. Their drawings, however, were more frequently colored in, were better proportioned, and showed greater joy and resilience. In contrast, other studies evaluating psychological features and quality of life have found that women - including girls - have worse results. ${ }^{48,49}$ Our results could be explained by greater concern for esthetic issues in girls and a higher level of maturity than in boys of the same age. To elucidate the differences between girls and boys and men and women in the experience of disease, future sex-based studies are required.

Age range was related to symmetry and the number of negative emotional indicators. Lack of symmetry can be explained by age in smaller children, who have acquired less pictorial skill. A notable finding, however, was the lack of symmetry in $65.4 \%$ of drawings by 12 - and 13 -year-olds, and in $54.5 \%$ of those by 10 - to 11 -year-old girls. Drawings with three or more negative emotional indicators were mainly rendered by adolescent boys. In contrast, stigma was more frequently perceived by girls; $16.7 \%$ of 12 - and 13 -year-old girls drew images suggesting stigma and low self-esteem. These findings could be related to the onset of adolescence and rejection of the disease. At this age, the psychological impact of T1D may be increased by the social stigma of having a disease and of feeling different and being treated as such. ${ }^{50}$ In industrialized countries, chronic disease is a tragedy because it fails to fit much-vaunted stereotypes of the healthy, vigorous, athletic, and independent individual. ${ }^{51}$

Participants with fewer hypoglycemic episodes produced more colorful drawings. The use of color was associated with 
joy and vitality, suggesting fewer symptoms and less anxiety in the personal, family, school, and social environment. $\mathrm{HbA}_{1 \mathrm{c}}$ was directly related to the number of negative emotional indicators. A lack of symmetry was directly related to lower $\mathrm{HbA}_{1 \mathrm{c}}$ levels, which may in turn be related to age, since younger children had lower $\mathrm{HbA}_{1 \mathrm{c}}$ levels and their drawings also showed less symmetry. No significant differences were found in the drawings by attendance at diabetes camps or patient associations. Significant differences, however, were found by the participant's birth order in the family. Smaller children with two or more older siblings showed more signs of stigma. The demands of metabolic control may make children with T1D feel different from their older siblings, who act as models. Children with T1D can have poor self-image and can perceive themselves as defective or as weaker than their siblings and peers, intensifying their feelings of inferiority and fear of rejection. ${ }^{52}$

A diagnosis of T1D marks a "before and after" in the lives of children and their families. A recent review reported that a mean of $35 \%$ of parents had psychological disturbances at the moment of diagnosis and that such disturbances persisted in $19 \%$ between 1 and 4 years later. These problems are associated with greater stress and anxiety in children, more problematic behavior, lower quality of life, and poorer T1D management. ${ }^{53}$ In the DAWN Youth survey, performed in 18 - to 25 -year-olds with diabetes, $25 \%$ of participants had insufficient psychological well-being; between $12 \%$ and $17 \%$ experienced shame and discrimination; $20 \%$ believed that diabetes impaired their work performance; and $39 \%$ their academic performance ${ }^{49}$ Because of the demands of metabolic control and treatment, coping with a chronic disease since childhood, and the physical, psychological, and social problems provoked by T1D, children, adolescents, and their families are in a vulnerable position, which could lead to future adaptation problems. Consequently, there is a need to explore new instruments that could foster participation and facilitate communication among children with T1D and their families and health teams. Drawing has provided valuable information and has also been considered effective in studies of children affected by physical abuse, neurological alterations, mental illnesses, and chronic diseases such as asthma, cancer, and AIDS; this technique has also been employed to elucidate the experience of natural catastrophes, child labor, and social changes. ${ }^{15-24,28}$

In the present study, in addition to the graphic drawingrelated variables (color, size, stroke, and symmetry), analysis of the general impression of the picture was useful as it helped us to consider all the drawing's dimensions, including the drawer's age and context. Also useful was the use of qualitative categories based on thematic content. The investigators participating in this study included nurse educators, teaching nurses with research experience, psychologists, and anthropologists, allowing our analysis to be performed from clinical, psychological, and sociocultural perspectives. Drawing is an inexpensive technique and is readily accepted by young people, including adolescents. Although further research is required, drawings and their explanations, in this study, allowed the impact of diabetes on young people and their families to be explored and aided communication with the health team, especially nurses.

\section{Study limitations}

Despite the large sample, which allowed an accurate and reliable statistical analysis, this study has certain limitations concerning participant follow-up. Some signs clearly indicating that the drawers were experiencing stigma, low self-esteem, or rejection of the disease could be confirmed by the health team. Sometimes the drawing revealed hitherto hidden problems. A psychological examination and longterm follow-up would have been beneficial. Also beneficial would have been analysis of other socioeconomic and cultural variables, such as family income, religious beliefs, and academic performance. Repeating the study to determine whether the main features of the drawings were maintained or modified by age or the course of T1D would also have been interesting.

\section{Conclusion}

In this study, drawings were a useful means by which to capture the emotions and possible difficulties in adapting to T1D, as well as to obtain information directly from the participants themselves. Future research should determine in greater depth the precise contributions that drawing can make to clinical practice. A potential pitfall is interpreting drawings from the interpretative framework of the adult; it is important that young people speak about their drawings, since this aids understanding of the drawings and helps the drawer to communicate difficulties to the health team and the family. Finally, the child's cultural context and age should be considered when interpreting drawings.

\section{Disclosure}

The authors report no conflicts of interest in this work. 


\section{References}

1. IDF Diabetes Atlas [webpage on the Internet]. Brussels, Belgium: International Diabetes Federation; 2011 [updated 2012]. Available from: http://www.idf.org/diabetesatlas/. Accessed November 26, 2011.

2. Abellana R, Ascaso C, Carrasco JL, Castell C, Tresserras R. Geographical variability of the incidence of type 1 diabetes in subjects younger than 30 years in Catalonia, Spain. Med Clin (Barc). 2009;132(12):454-458.

3. Isla Pera P, Moncho Vasallo J, Guasch Andreu O, Torras Rabasa A. Alignment of the Kübler-Ross grief cycle phases with the process of adaptation to type 1 diabetes mellitus. Endocrinol Nutr. 2008;55:78-83. English, Spanish.

4. Isla Pera P. Repercusiones de la diabetes en el niño and el adolescente [Diabetes mellitus in teenagers]. Rev ROL Enf. 2010;33(7-8):528-534.

5. Grey M, Cameron ME, Lipman TH, Thurber FW. Psychosocial status of children with diabetes in the first 2 years after diagnosis. Diabetes Care. 1995;18:1330-1336.

6. Fritsch SL, Overton MW, Robbins DR. The interface of child mental health and juvenile diabetes mellitus. Pediatr Clin North Am. 2011;58: 937-954.

7. Reynolds KA, Helgeson VS. Children with diabetes compared to peers: depressed? Distressed? A meta-analytic review. Ann Behav Med. 2011;42:29-41.

8. Ginsburg KR, Howe CJ, Jawad AF, et al. Parents' perceptions of factors that affect successful diabetes management for their children. Pediatrics. 2005;116:1095-1104.

9. Harris MA, Freeman KA, Beers M. Family therapy for adolescents with poorly controlled diabetes: initial test of clinical significance. J Pediatr Psychol. 2009;34:1097-1107.

10. Weinger K, O’Donnell KA, Ritholz MD. Adolescent views of diabetesrelated parent conflict and support: a focus group analysis. J Adolesc Health. 2001;29(5):330-336.

11. Jiménez Yanez C, Martínez Soto Y. Visiones y representaciones de estudiantes a Través del Dibujo. [Visions and representations of students through the drawing]. Rev Mex Orient Educ. [Online]. 2011;8.

12. Llanderas P, Méndez M. Educar en valores - educación para la salud [Teaching values - health education] [webpage on the Internet]. Madrid: Ministerio de Educación and Ciencia (MEC); 1995. Available from: http://w3.cnice.mec.es/recursos/primaria/transversales/salud.htm. Accessed April 1, 2008. Spanish.

13. Hammer EF. Clinical Applications of Projective Drawings. Springfield, IL: Charles C Thomas; 1967.

14. Machover K. Personality Projection in the Drawings of the Human Figure. Springfield, IL: Charles C Thomas; 1949.

15. Councill T. Art therapy with pediatric cancer patients: helping normal children cope with abnormal circumstances. Art Therapy: journal of the American Art Therapy Association. 1993;10:78-87.

16. Looman WS. A developmental approach to understanding drawings and narratives from children displaced by Hurricane Katrina. J Pediatr Health Care. 2006;20:158-166.

17. Balottin U, Termine C, Quadrelli M, Brondolo S, Baratelli S, Zambonin F. Brothers of children with a neurological disease: difficulties and affective needs. Study of a clinical sample. Encephale. 2006;32:60-66. French.

18. Massimo LM, Zarri DA. In tribute to Luigi Castagnetta-drawings. A narrative approach for children with cancer. Ann N Y Acad Sci. 2006;1089:xvi-xxiii.

19. Edelstein K, Dennis M, Copeland K, et al. Motor learning in children with spina bifida: dissociation between performance level and acquisition rate. $J$ Int Neuropsychol Soc. 2004;10:877-887.

20. Gabriels RL, Wamboldt MZ, McCormick DR, Adams TL, McTaggart SR. Children's illness drawings and asthma symptom awareness. J Asthma. 2000;37:565-574.

21. Rollins JA. Tell me about it: drawing as a communication tool for children with cancer. J Pediatr Oncol Nurs. 2005;22:203-221.

22. Panez R. El Lenguaje Silencioso de los Niños. Un Estudio Peruano Sobre los Derechos del Niño Desde su Producción Creativa. [The silent language of children. A Peruvian study on children's rights from their creative output]. Lima: Panez and Silva Ediciones; 2004. Spanish.
23. Rogers R. Diagnostic, expanatory, and detection models of Munchausen by proxy: extrapolations from malingering and deception [sic]. Child Abuse Negl. 2004;28:225-238.

24. Koppitz E. El Drawing de la Figura Humana en los Niños. [The drawing of the human figure in children]. 5th ed. Buenos Aires: Guadalupe; 1976. Spanish.

25. Welsh $\mathrm{J}$, Instone $\mathrm{S}$. Use of drawings by children in the pediatric office. In: Dixon S, Stein M, editors. Encounters with Children: pediatric Behavior and Development. St, Louis: Mosby; 2000; 571-589.

26. Núñez de Arco J, Echevarria ML, Zapata R. El dibujo como expresión de la agresividad. Revista Española de Psiquiatría Forense. [Drawing as an expression of aggression]. Spanish Journal of Forensic Psychiatry.1996;0:37-44. Spanish.

27. ter Laak J, de Goede M, Aleva A, van Rijswijk P. The Draw-A Person Test: an indicator of children's cognitive and socioemotional adaptation? J Genet Psychol. 2005;166:77-93.

28. Williams SD, Wiener J, MacMillan H. Build-a-Person Technique: an examination of the validity of human-figure features as evidence of childhood sexual abuse. Child Abuse and Negl. 2005;29:701-713.

29. Eno L, Elliot C, Woehlke P. Koppitz emotional indicators in the human-figure drawings of children with learning problems. J Spec Educ. 1981;15:459-470.

30. Garaigordobil M, Álvarez Z, Carralero V. Conducta antisocial en niños de 10 a 12 years: factores de personalidad asociados and variables predictoras. [Antisocial behavior in children aged 10-12 years: Personality factors associated and predictive variables]. Análisis Y Modificacion de Conducta. 2004;130:241-271. Spanish.

31. Abreu M, Vanja B. Emotional indicators of sexual abuse in the projective drawings of human figure. Revista de Terapia Sexual y de Pareja. [Spanish]. 2006;25:51-73.

32. Aldridge J, Lamb ME, Sternberg KJ, Orbach Y, Esplin PW, Bowler L. Using a human figure drawing to elicit information from alleged victims of child sexual abuse. J Consult Clin Psychol. 2004;72:304-316.

33. Sturner R, Rothbaum F, Visintainer M, Wolfer J. The effects of stress on children's human figure drawings. J Clin Psychol. 1980;36: 324-331.

34. Boyd JR, Hunsberger M. Chronically ill children coping with repeated hospitalizations: their perceptions and suggested interventions. J Pediatr Nurs. 1998;13:330-342.

35. Milousheva J, Kobayashi N, Matsui I. Psychosocial problems of children and adolescents with a chronic disease: coping strategies. Acta Paediatr Jpn. 1996;38:41-45.

36. Art and Poetry [webpage on the Internet]. Children With Diabetes, Inc [updated November 23, 2010]. Available from: http://www. childrenwithdiabetes.com/art/. Accessed January 4, 2010.

37. Hernández Pina F, Buendía Eisman L, Colás Bravo P. Métodos de Investigación en Psicopedagogía. [Research Methods in Psychology]. Madrid: McGraw Hill; 1998. Spanish.

38. García A. Selección de Lecturas de la Evaluación and Diagnóstico Infantil. La Habana: ENPES; 1983;18-25.

39. Traube T. La valor diagnostique dessins des enfants difficiles. [The diagnostic value of drawings of problem children]. Archives de Psychologie. 1937;26:285-309. Available from: http://psycnet.apa.org/ index.cfm?fa=search.displayRecord\&UID=1938-04442-001.

40. Waehner TS. Interpretation of spontaneous drawings and paintings. Series: Genetic Psychology Monograph 1946: 33:3-70. Provincetown, Mass, USA. The Journal Press, 1946. Available from: http://www.worldcat.org/title/interpretation-of-spontaneous-drawings-and-paintings/ocl $\mathrm{c} / 223287717$ ?referer=br\&ht=edition.

41. Alonso García OS. Dibujos Proyectivos. Aplicación e Interpretación. [Projective drawings. Application and interpretation]. La Habana: Ciencias Médicas; 2010. Spanish.

42. Furth GM. El Secreto Mundo of the Drawings. [The secret world of drawings]. Barcelona: Luciernaga; 1992. Spanish.

43. LaPlantine F. Anthropologie de la Maladie [Anthropology of Disease]. Paris: Éditions Payot; 1992. French. 
44. Danne T, Kordonouri O. ¿Cuál es la gran diferencia de la diabetes infantil? [What is so different about diabetes in children? Diabetes Voice: bulletin of the International Diabetes Federation]. Diabetes Voice. 2007;52:16-19. Spanish.

45. Edge JA, Ford-Adams ME, Dunger DB. Causes of death in children with insulin dependent diabetes 1990-1996. Arch Dis Child. 1999;81:318-323.

46. Robinson N, Lloyd CE, Stevens LK. Social deprivation and mortality in adults with diabetes mellitus. Diabet Med. 1998;15:205-212.

47. Minar VM. Art-therapy and cancer. Images of the hurter and healer. In: Malchiodi C, editor. Medical Art-Therapy with Adults. London: Jessica Kingsley Publishers; 1999;227-242.

48. Faulkner MS. Quality of life for adolescents with type 1 diabetes: parental and youth perspectives. Pediatr Nurs. 2003;29:362-368.

49. Peyrot M. ¿Cómo se percibe la diabetes? Resultados de la encuesta DAWN Youth. [How is diabetes perceived? The results of the DAWN Youth survey. Diabetes Voice: bulletin of the International Diabetes Federation]. Diabetes Voice. 2008;53:9-13. Spanish.
50. Gil Roales-Nieto J, Vílchez Joya R. Diabetes, Intervención Psicológica. [Diabetes, psychological intervention]. Madrid: Eudema Psicología; 1993. Spanish.

51. Canals J. Salut i malaltia. Consideracions des de l'antropologia social. [Health and disease. Considerations from social anthropology]. In: Sáez S, Marqués F, Isla P, editors. Promoció i Educació per a la Salut. Lleida: Edicions de la Universitat de Lleida; 1995. Spanish.

52. Meldman LS. Diabetes as experienced by adolescents. Adolescence. 1987;22:433-444.

53. Whittemore R, Jaser S, Chao A, Jang M, Grey M. Psychological experience of parents of children with type 1 diabetes: a systematic mixed-studies review. Diabetes Educ. 2012;38:562-579.

\section{Publish your work in this journal}

Patient Preference and Adherence is an international, peer-reviewed, open access journal focusing on the growing importance of patient preference and adherence throughout the therapeutic continuum. Patient satisfaction, acceptability, quality of life, compliance, persistence and their role in developing new therapeutic modalities and compounds to optimize clinical outcomes for existing disease states are major areas of interest. This journal has been accepted for indexing on PubMed Central. The manuscript management system is completely online and includes a very quick and fair peer-review system. Visit http://www.dovepress.com/ testimonials.php to read real quotes from published authors.

Submit your manuscript here: http://www.dovepress.com/patient-preference-and-adherence-journal 